\title{
Factors associated with the rectal temperature of Holstein dairy cows during the first 10 days in milk
}

\author{
J. R. Wenz, ${ }^{1}$ D. A. Moore, and R. Kasimanickam \\ Department of Clinical Sciences, Washington State University, Pullman 99164
}

\begin{abstract}
Daily evaluation of rectal temperature (RT) during the first $10 \mathrm{~d}$ in milk (DIM) is used to facilitate the early identification of postpartum complications, particularly metritis in dairy cows. The factors associated with RT of postpartum dairy cows have not been clearly established and the RT threshold used to define fever has been variable. The objectives were to identify factors associated with the RT of postpartum dairy cows and provide descriptive statistics of the RT during the first 10 DIM to clarify the normal range of RT for cows. Daily RT was evaluated from 1 to 10 DIM for all cows calving during 2 consecutive summers on a single 1,500-cow Holstein dairy. Cows were placed into metabolic/digestive (METB), infectious (INF), and no recorded disease (NONE) groups based on disease diagnoses during the first 10 DIM. Cows were grouped based on calving difficulty and parity. Multiple linear regression models with repeated measures were used to evaluate the factors associated with RT. Three hundred and ninety-two cows were evaluated, of which $45 \%$ were primiparous and $32 \%$ required assistance at calving. No difference was observed in calving assistance by parity. First disease diagnoses peaked in the INF and METB groups at 3 and 1 DIM, respectively. The RT of primiparous cows was 0.1 to $0.2^{\circ} \mathrm{C}$ higher than that of multiparous cows from 1 to 8 DIM, accounting for calving difficulty, twin births, month of calving, and disease group in the model. The INF group cows had a higher RT than did NONE group cows (38.9 \pm 0.04 to $39.2 \pm$ 0.73 vs. $38.7 \pm 0.03^{\circ} \mathrm{C}$, respectively) on each of the first 10 DIM, which was approximately $0.6^{\circ} \mathrm{C}$ higher from 3 to 5 DIM. The RT of cows with metritis was at least $0.1^{\circ} \mathrm{C}$ higher $\left(38.8 \pm 0.05^{\circ} \mathrm{C}\right)$ than that of NONE group cows beginning $4 \mathrm{~d}$ before diagnosis. The mean RT of primiparous, defined healthy (NONE group) cows was $38.8 \pm 0.02^{\circ} \mathrm{C}$, with an upper normal limit (mean +2 $\mathrm{SD})$ of $39.6^{\circ} \mathrm{C}$. The mean RT of multiparous cows in the NONE group during the first 10 DIM was $38.7 \pm$
\end{abstract}

Received October 11, 2010.

Accepted December 20, 2010.

${ }^{1}$ Corresponding author: jrwenz@vetmed.wsu.edu $0.01^{\circ} \mathrm{C}$, with an upper normal limit of $39.5^{\circ} \mathrm{C}$. The RT of dairy cattle during the first 10 DIM was associated with parity, month of calving, and an infectious disease diagnosis, particularly the diagnosis of metritis. The normal RT of dairy cattle in the immediate postpartum period, during the warm summer months, is potentially higher than that generally reported.

Key words: postpartum, rectal temperature, dairy cattle

\section{INTRODUCTION}

Daily evaluation of the rectal temperature (RT) of dairy cows is the most common component of postpartum cow monitoring programs designed to facilitate early identification and management of postpartum complications, particularly metritis (Smith and Risco, 2005). The normal body temperature of cattle is reported as $38.6 \pm 0.5^{\circ} \mathrm{C}$ (Andersson and Jónasson, 1993); however, the RT threshold above which a postpartum cow is considered febrile has varied considerably. In a metritis treatment study Smith et al. (1998) considered RT $>39.2^{\circ} \mathrm{C}$ a fever. Other studies of metritis and retained fetal membranes used RT thresholds of $39.5^{\circ} \mathrm{C}$ (Stevens et al., 1995; Drillich et al., 2001) and $39.7^{\circ} \mathrm{C}$ (Dinsmore et al., 1996; Sheldon et al., 2004). Threshold RT used in monitoring programs have differed between primiparous $\left(39.4^{\circ} \mathrm{C}\right)$ and multiparous cows $\left(39.7^{\circ} \mathrm{C}\right.$; Kristula et al., 2001), although we are aware of no published data to support this practice.

Contrasting with the previously mentioned studies focused on uterine disease treatment regimens, a study by Wagner et al. (2008) had a specific objective of describing normal RT in healthy postpartum dairy cows compared with those that developed clinical disease. That study found 66 and $49 \%$ of healthy postpartum dairy cattle had at least 1 RT measurement greater than the commonly used threshold temperatures of $39.5^{\circ} \mathrm{C}$ and $39.7^{\circ} \mathrm{C}$, respectively, during the first 10 DIM. Kristula et al. (2001) reported in a retrospective study that $48 \%$ of normal cows had a $\mathrm{RT}>39.2^{\circ} \mathrm{C}$ during the first 10 DIM when RT was measured daily before 0700 $\mathrm{h}$. The factors that influence RT during the first 10 DIM and an appropriate upper threshold temperature 
to differentiate normal and potentially abnormal cows remain unclear.

The primary objective was to evaluate factors potentially associated with RT of dairy cattle in the immediate postpartum period. The secondary objectives were to provide descriptive statistics of the daily RT of dairy cattle during the first 10 DIM based on health status and determine the normal temperature range for healthy postpartum dairy cattle. Such data should prove useful in interpretation of RT measurements of postpartum cows and refinement of postpartum disease monitoring protocols.

\section{MATERIALS AND METHODS}

\section{Cows and Herd Management}

The study was conducted during 2 consecutive summers, from May 27 to July 15, 2005, and May 29 to July 20, 2006, on a single commercial dairy farm with approximately 1,500 lactating, Holstein cows in Colorado. Primiparous and multiparous cows were housed together in a dry lot pen with a straw bedding pack from 3 wk before the anticipated calving date until the day of calving. Following parturition, all cows spent 1 to $2 \mathrm{~d}$ in a postpartum pen until their milk was deemed salable, after which they moved to the first lactating cow pen (fresh pen) in which they stayed until 20 to 30 DIM. Cows in both pens were housed on sand-bedded freestalls, were fed a TMR, and milked twice daily in the postpartum pen and 3 times daily in the fresh pen.

\section{Study Design and Definitions}

The study followed a prospective observational design. All enrolled cows were subjected to once-daily evaluation of RT by study personnel from 1 to 10 DIM using a digital thermometer (GLA M500HPDT, Agricultural Electronics, San Luis Obispo, CA) from 0600 to 0800 h, immediately after the morning milking. The thermometer had an accuracy and resolution of $0.1^{\circ} \mathrm{C}$ and was equipped with an angled $\left(42^{\circ}\right)$ metal probe inserted to the angle $(11 \mathrm{~cm})$. Ambient temperature was recorded once daily by study personnel from the farm weather station (WS-2000/MKIII, RainWise, Inc., Bar Harbor, $\mathrm{ME}$ ), located approximately $90 \mathrm{~m}$ from the barn, following completion of RT evaluation. A brief physical exam (evaluation of hydration, rumen contraction rate, and transrectal uterine massage to express contents) was performed by study personnel on cows with RT $>39.4^{\circ} \mathrm{C}$ once daily in the morning. Observations made by study personnel were not shared with farm personnel examining postpartum cows. Postpartum cow monitoring by farm personnel consisted of visual observation to identify cows that appeared abnormal (e.g., signs of depression, dehydration, anorexia, low rumen fill, and decreased udder fill). Metritis was diagnosed in cows with abnormal uterine fluid contents (serous, redbrown to gray colored, with a fetid odor) spontaneously discharged or expressed from the vulva by transrectal uterine massage with or without RT $>39.4^{\circ} \mathrm{C}$. Metritis diagnosis by farm personnel required a cow have RT $>39.4^{\circ} \mathrm{C}$ and only cows diagnosed by farm personnel were treated. Metritis treatment performed by farm personnel was determined by farm protocol and typically consisted of i.m. ceftiofur sodium $(2.2 \mathrm{mg} / \mathrm{kg})$ for $5 \mathrm{~d}$ and supportive care as needed. Calving difficulty was defined as $1=$ unassisted, $2=$ easy pull, $3=$ hard pull, or $4=$ veterinary assistance required. Mastitis was identified at milking time based on the presence of abnormal milk, mammary gland, or both. Pneumonia was diagnosed based on tachypnea and $\mathrm{RT}>39.4^{\circ} \mathrm{C}$ in the absence of other identifiable clinical disease. Retained placenta was diagnosed based on the presence of fetal membranes protruding from the vulva $\geq 24 \mathrm{~h}$ after calving. Digestive upset was diagnosed in cows that were anorectic and had a decreased rumen contraction rate. Calving and postpartum health events were diagnosed by farm personnel and recorded in the farm's database.

\section{Data Management}

Data for parity, calving difficulty, twinning, and farm personnel-identified health events were obtained from the on-farm dairy management software (Dairy Comp 305, Valley Ag Software, Tulare, CA). Accuracy of computer-recorded health events was confirmed by comparison with written treatment records. Cows were grouped based on the occurrence of farm personnelidentified health events and study personnel-identified metritis occurring during the first 10 DIM. Those with retained fetal membranes, milk fever, digestive upset, and diarrhea with a rectal temperature $<39.4^{\circ} \mathrm{C}$ were placed in the metabolic/digestive disease (METB) group. Cows with mastitis, metritis, or pneumonia were placed in the infectious disease (INF) group. Cows with no recorded health events were placed in the NONE group. Cows with both INF and METB diseases during the first 10 DIM were placed in the INF category. Cows were grouped by calving difficulty (EASE) into unassisted and assisted groups and by parity into primiparous and multiparous groups.

\section{Statistical Analyses}

A priori we determined that EASE, twin births, parity, month of calving, and infectious disease were 
biologically plausible factors associated with RT during the first 10 DIM, and variables representing these factors were included in all models. Potential interactions between those variables were evaluated for homogeneity of proportions by chi-squared analysis. Associations between RT and the factors studied were evaluated in a repeated measures ANOVA model using PROC MIXED (SAS version 9.2., SAS Institute, Inc., Cary, NC). The autoregressive order-1 covariate structure was used, as it resulted in the model with the lowest Akaike information criterion value (a relative measure of the goodness of fit for competing statistical models). Interaction terms with an $\alpha<0.10$ were included in the model. Homogeneity of proportions between groups was evaluated by chi-squared analysis.

The least squares means \pm standard error $R T$ of cows grouped by variables with a significant between-subjects effect was compared at each DIM from 1 to 10 with a Tukey-Kramer adjustment to account for experimentwise error rate associated with multiple comparisons. The least squares means \pm standard error $R T$ relative to the day of metritis diagnosis of cows with metritis was compared with the RT of parity and DIM-matched cows from the NONE group using PROC MIXED (SAS version 9.2., SAS Institute, Inc.). Day 0 was defined as the DIM of metritis diagnosis for cows with metritis and the same DIM for the parity-matched cow from the NONE group. Days -1 to -5 were assigned to the $5 \mathrm{~d}$ preceding the diagnosis DIM and d 1 to 5 for the $5 \mathrm{~d}$ following. The normal range of RT during the first 10 DIM was determined based on the mean $\mathrm{RT} \pm 2 \mathrm{SD}$ of cows in the NONE group for each parity group.

\section{RESULTS}

A total of 413 cows was enrolled in the study. Twenty-one cows were removed from the study because 1 or more RT data points were missing during the first 10 DIM, leaving 392 cows that were included in the analysis. During the first 10 DIM, $13(7 \%), 1(6 \%)$, and 0 cows were removed from the farm (sold or died) in the INF, METB, and NONE disease groups, respectively. Primiparous cows accounted for $45 \%$ of subjects, $32 \%$ of all cows were provided assistance at calving, and $6 \%$ delivered twins. No difference in cows requiring assistance at calving was observed between primiparous $(33 \%)$ versus multiparous $(32 \%)$ animals $(P=0.829)$. In total, 193 cows (49\%) and 199 cows (51\%) were enrolled in 2005 and 2006, respectively. Over both years of the study, $70 \%$ of cows enrolled calved in June and the remaining $30 \%$ calved in July. Over the course of both years, the ambient temperature at the completion of daily RT determination $(0800 \mathrm{~h})$ ranged from 7.2 to $25^{\circ} \mathrm{C}$, steadily increasing over the course of each study period. An average of 4 cows calved per day and 40 to 60 cows between 1 and 10 DIM were evaluated daily at the midpoint of each study period.

\section{Disease Diagnoses in Cows During the First 10 DIM}

Disease was diagnosed in 195 cows (50\%) during the first 10 DIM. The percentage of cows in the INF, METB, and NONE groups was 45, 4.6, and 50\%, respectively. Sixty-four cows in the INF group (36\%) also had a metabolic/digestive health event recorded during the first 10 DIM. Sixty-three percent of those cows were multiparous. Cows in the INF group with a METB disease diagnosis had slightly higher $\mathrm{RT}\left(0.2^{\circ} \mathrm{C}\right)$ during 1 to 5 DIM; however, METB disease was not associated with RT among cows in the INF group $(P=0.307)$. Retained placenta was diagnosed in 60 cows, 58 of which were in the INF group. A higher percentage of cows with an assisted calving (65\%) had an infectious disease diagnosis compared with those with an unassisted calving $(36 \% ; P<0.001)$; however, no differences in METB group disease diagnoses existed (Table 1). Infectious disease diagnosis tended to be higher in primiparous cows $(51 \%)$ compared with that in multiparous cows $(41 \% ; P=0.053)$.

Mastitis, metritis, and pneumonia alone were recorded during the first 10 DIM for 5.6, 30, and $1.3 \%$ of cows in the study, respectively (Table 2). Compared with multiparous cows, a higher percentage of primiparous cows had a metritis diagnosis only $(P=0.004)$ or metritis combined with another infectious disease diagnosis $(P$ $=0.021$ ) during the first 10 DIM (Table 2). The median DIM at diagnosis was 2, 5, and 3 for mastitis, metritis, and pneumonia alone, respectively. The median DIM at diagnosis was 4,5 , and 7 for digestive upset, diarrhea, and displaced abomasum alone, respectively. Disease diagnoses in the INF and METB groups peaked at 3 and 1 DIM, respectively (Figure 1).

\section{Rectal Temperature Measurements During the First 10 DIM}

The highest mean RT was first observed by 3 DIM for cows in the INF and METB disease diagnosis groups (Table 3). Greater variability in RT was observed in the INF group compared with the METB and NONE groups. Variation in RT was greatest on DIM 3 to 5,3 , and 3 for the INF, METB, and NONE groups, respectively (Table 3 ).

\section{Factors Associated with RT During the First 10 DIM}

Twin birth and EASE were not associated with RT during the first 10 DIM, accounting for parity, month 
Table 1. Number and percent (in parentheses) of cows in a disease diagnosis group during the first 10 DIM by calving ease and parity

\begin{tabular}{lcccc}
\hline & \multicolumn{4}{c}{ Disease diagnosis group $^{1}$} \\
\cline { 2 - 5 } Factor & $\begin{array}{c}\text { Infectious } \\
(\mathrm{n}=177 ; 45 \%)\end{array}$ & $\begin{array}{c}\text { Metabolic/digestive } \\
(\mathrm{n}=18 ; 4.6 \%)\end{array}$ & $\begin{array}{c}\text { None } \\
(\mathrm{n}=197 ; 50 \%)\end{array}$ & $\begin{array}{c}\text { All } \\
(\mathrm{n}=392)\end{array}$ \\
\hline Calving ease & $95(36)^{\mathrm{a}}$ & $12(4.5)$ & $158(60)^{\mathrm{a}}$ & 265 \\
Unassisted & $82(65)^{\mathrm{b}}$ & $6(4.7)$ & $39(31)^{\mathrm{b}}$ & 127 \\
Assisted & $90(51) \dagger$ & $9(5.1)$ & $79(44)^{\mathrm{a}}$ & 178 \\
Parity & $87(41) \dagger$ & $9(4.2)$ & $118(55)^{\mathrm{b}}$ & 214 \\
Primiparous & Multiparous & &
\end{tabular}

${ }^{\mathrm{a}, \mathrm{b}}$ Values in a column within a factor heading with different superscripts were different $(P<0.001)$.

${ }^{1}$ Cows in the infectious group were diagnosed with mastitis, metritis, or pneumonia; cows in the metabolic/ digestive group were diagnosed with milk fever, digestive upset, retained placenta, displaced abomasum, or diarrhea, with a rectal temperature $<39.4^{\circ} \mathrm{C}$; and those in the none group had no disease diagnoses during the first 10 DIM. Cows in the infectious group may have also had a metabolic/digestive disease diagnosis.

$\dagger$ Values in a column within a factor heading were different $(P=0.053)$.

of calving, DIM, and disease group (Table 4). When the disease group variable was removed from the model, associations between RT and twin birth $(P=0.007)$, as well as RT and EASE $(P=0.040)$, were identified, accounting for parity, month of calving, and DIM. When only cows in the NONE disease group were included in the model, neither twin birth $(P=0.351)$ nor EASE $(P$ $=0.996)$ were associated with RT.

Parity was associated with RT $(P<0.001)$ independent of DIM $(P=0.2479)$, accounting for EASE, twin births, month of calving, and disease group. The least squares mean RT was 0.1 to $0.2^{\circ} \mathrm{C}$ higher in primiparous versus multiparous cows from 1 to 8 DIM $(P<$ 0.049 ; Figure 2 ). When only cows in the NONE disease group were included in the model, parity was still associated with RT $(P=0.004)$, which was dependent on DIM $(P=0.004)$. The RT was 0.1 to $0.2^{\circ} \mathrm{C}$ higher in primiparous versus multiparous cows during each of the first 5 DIM, but was not different on DIM 6 to 10.

Month of calving (June or July) was associated with RT, accounting for EASE, twin births, disease group, and DIM (Table 4). The RT of cows that calved in

Table 2. Number and percent (in parentheses) of 392 Holstein dairy cows with 1 or more disease diagnoses during the first 10 DIM by parity

\begin{tabular}{|c|c|c|c|}
\hline \multirow[b]{2}{*}{$\begin{array}{l}\text { Disease } \\
\text { diagnosis }^{1}\end{array}$} & \multicolumn{3}{|c|}{ Parity } \\
\hline & $\begin{array}{c}\text { Primiparous } \\
(\mathrm{n}=178)\end{array}$ & $\begin{array}{l}\text { Multiparous } \\
(\mathrm{n}=214)\end{array}$ & $\begin{array}{c}\text { All } \\
(\mathrm{n}=392)\end{array}$ \\
\hline Infectious & $90(51) \dagger$ & $87(41) \dagger$ & $177(45)$ \\
\hline Mastitis & $10(5.6)$ & $12(5.6)$ & $22(5.6)$ \\
\hline Metritis & $66(37)^{\mathrm{a}}$ & $50(23)^{b}$ & $116(30)$ \\
\hline Pneumonia (pneum.) & $1(0.6)$ & $4(1.9)$ & $5(1.3)$ \\
\hline Mastitis + pneum. & $2(1.1)$ & $3(1.4)$ & $5(1.3)$ \\
\hline Metritis + mastitis & $5(2.8)$ & $7(3.3)$ & $12(3.1)$ \\
\hline Metritis + pneum. & $5(2.8)$ & $9(4.2)$ & $14(3.6)$ \\
\hline Metritis + mastitis + pneum. & $1(0.6)$ & $2(0.9)$ & $3(0.8)$ \\
\hline Total cows with metritis & $77(43)^{\mathrm{a}}$ & $68(32)^{\mathrm{b}}$ & $145(37)$ \\
\hline Metabolic/digestive & $9(5.1)$ & $9(4.2)$ & $18(4.6)$ \\
\hline Rumen atony & $6(3.4)$ & $3(1.4)$ & $9(2.3)$ \\
\hline $\mathrm{RP}^{2} \pm$ rumen atony & $1(0.6)$ & $0(0)$ & $1(0.3)$ \\
\hline Diarrhea $^{3}$ & $1(0.6)$ & $2(0.9)$ & $3(0.8)$ \\
\hline Displaced abomasum & $1(0.6)$ & $2(0.9)$ & $3(0.8)$ \\
\hline Other combinations ${ }^{4}$ & $0(0)$ & $2(0.9)$ & $2(0.5)$ \\
\hline \multicolumn{4}{|c|}{${ }^{\mathrm{a}, \mathrm{b}}$ Values within a row with different superscripts are different $(P=0.011)$. } \\
\hline \multicolumn{4}{|c|}{$\begin{array}{l}{ }^{1} \text { Cows in the infectious group may also have had a metabolic/digestive disease diagnosis. Cows in the } 1 \\
\text { bolic/digestive group did not have any infectious disease diagnoses. } \\
{ }^{2} \text { Retained placenta. } \\
{ }^{3} \text { Cows with diarrhea had rectal temperature }<39.4^{\circ} \mathrm{C} \text {. } \\
\dagger \text { Includes } 4 \text { cows diagnosed with milk fever with } 2 \text { or more other metabolic/digestive disease diagnoses. } \\
{ }^{4} \text { a row are different }(P=0.053) \text {. }\end{array}$} \\
\hline
\end{tabular}


July $\left(39.0 \pm 0.03^{\circ} \mathrm{C}\right)$ was higher than that of cows that calved in June $\left(38.9 \pm 0.04^{\circ} \mathrm{C} ;(P<0.001)\right.$; however, the association between month of calving and RT was not influenced by DIM $(P=0.132)$. The daily ambient temperature during July was higher $\left(19.2 \pm 0.1^{\circ} \mathrm{C}\right)$ than that observed in June $\left(15.8 \pm 0.1^{\circ} \mathrm{C}\right)$ over both years $(P<0.001)$.

Disease group was associated with RT during the first 10 DIM $(P<0.001)$ and the influence of disease group on RT varied with DIM $(P<0.001)$ accounting for EASE, twin births, parity, and month of calving (Table 4). Cows in the INF group had a higher RT than that of the NONE cows on each of the first 10 DIM $(P<0.001)$ and the difference was the greatest (approximately $0.6^{\circ} \mathrm{C}$ ) from 3 to 5 DIM (Figure 3 ). The RT of cows in the MET group were not different than those in the NONE group during the first 10 DIM, but were lower than those in the INF group from 3 to 7 DIM $(P<0.014$; Figure 3$)$.

\section{Rectal Temperature Relative to Metritis Diagnosis During the First 10 DIM}

The RT of cows with metritis $(\mathrm{n}=145)$ peaked on the day of diagnosis $39.6 \pm 0.1^{\circ} \mathrm{C}$ and was $0.8^{\circ} \mathrm{C}$ higher than that of parity-matched healthy cows $(\mathrm{n}=145, P$ $=0.001$ ) at a similar DIM (Figure 4 ). The RT of cows with metritis was at least $0.2^{\circ} \mathrm{C}$ higher than that of healthy cows at a similar DIM, beginning $4 \mathrm{~d}$ before the metritis diagnosis, and continued higher for $4 \mathrm{~d}$ after the diagnosis $(P<0.001 ;$ Figure 4$)$.

\section{Determination of the Normal Range of Rectal Temperature During the First 10 DIM}

The normal range of RT in postpartum Holstein dairy cattle was calculated as the average daily RT over the first 10 DIM \pm 2 standard deviations of defined healthy (NONE disease group) cows. A normal range was calculated separately for primiparous and multiparous groups because RT was associated with parity when all cows and only those in the NONE group were considered. The mean RT of primiparous cows in the NONE group during the first 10 DIM ( $\mathrm{n}=790$ total observations) was $38.8 \pm 0.02^{\circ} \mathrm{C}$, with a lower normal limit of $37.9^{\circ} \mathrm{C}$ and an upper normal limit of $39.6^{\circ} \mathrm{C}$. Eleven (14\%) primiparous cows had at least $1 \mathrm{RT}$ measurement $>39.6^{\circ} \mathrm{C}$. Seven $(9 \%)$ had a single day with an RT exceeding the normal upper limit. Only $3.8 \%$ of NONE group versus $36 \%$ of INF group primiparous cows had an RT measurement exceeding the normal upper limit for 2 or more consecutive days. The mean RT of multiparous cows in the NONE group during the first 10 DIM ( $\mathrm{n}=1,180$ observations) was $38.7 \pm 0.01^{\circ} \mathrm{C}$, with

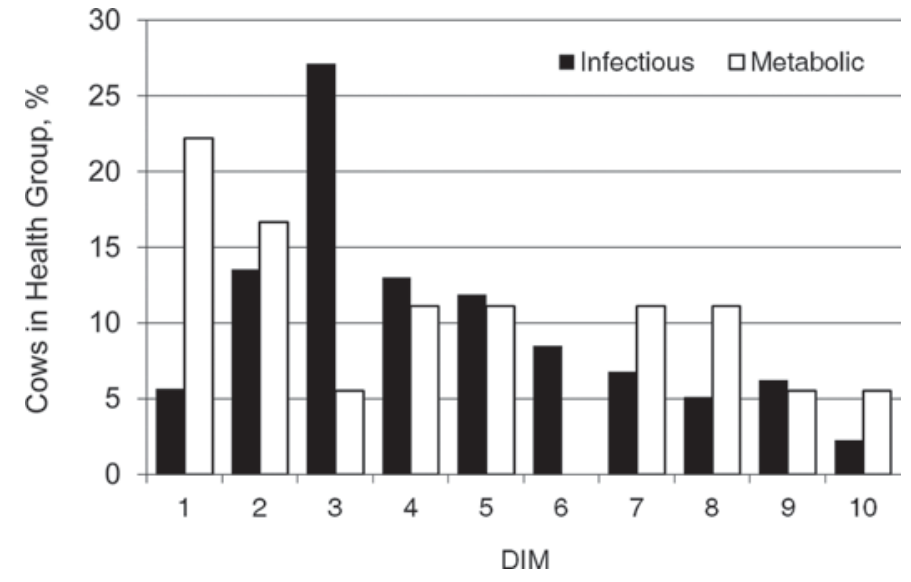

Figure 1. Percentage of Holstein dairy cows in a health group by the DIM of the first disease diagnosis during the first 10 DIM with an infectious (black bars, $\mathrm{n}=177$ ) or metabolic (white bars, $\mathrm{n}=18$ ) health event. The infectious group included cows with mastitis, metritis, and pneumonia. Cows in the infectious group may have also had a metabolic health event recorded during the first 10 DIM. The metabolic group included cows with milk fever, digestive upset, retained placenta, displaced abomasum, and diarrhea with a rectal temperature $<39.4^{\circ} \mathrm{C}$ only.

a lower limit of $37.9^{\circ} \mathrm{C}$ and an upper limit of $39.5^{\circ} \mathrm{C}$. Eighteen (15\%) multiparous cows had at least 1 RT measurement $>39.5^{\circ} \mathrm{C}$. Thirteen $(11 \%)$ had a single day with an RT exceeding the normal upper limit. For multiparous cows, only $2.5 \%$ of NONE group versus $34 \%$ of INF group cows had 2 or more consecutive days with an $\mathrm{RT}>39.5^{\circ} \mathrm{C}$. Across both parities, $69 \%$ of NONE group cows exceeding their respective threshold RT (n = 29) did so for only 1 of the first 10 DIM.

\section{DISCUSSION}

Infectious postpartum disease, particularly metritis, was associated with the greatest observed difference in RT of cows during the first 10 DIM. The greatest difference between the INF and NONE groups (approximately $0.6^{\circ} \mathrm{C}$ ) was observed from 3 to 5 DIM (Figure 3 ) a time that corresponded to the highest frequency of first infectious disease diagnoses (Figure 1). Burfeind et al. (2010) confirmed the repeatability of RT measurements in dairy cows. They identified thermometer type and penetration depth into the rectum as 2 important factors that could potentially influence the result of an individual measurement. Such variation was decreased in the current study by use of a single thermometer and a consistent penetration depth of $11 \mathrm{~cm}$ for all measurements. Previous studies have concluded that RT alone is not adequate to determine if antibiotic treatment is indicated, primarily because a high percentage of "healthy" cows had an elevated RT and would potentially receive unnecessary treatment (Kristula et 
Table 3. Number of cows, ${ }^{1}$ mean, SD, SE, minimum (Min.), maximum (Max.), and median for rectal temperatures in ${ }^{\circ} \mathrm{C}$ of Holstein dairy cows during the first 10 DIM by disease diagnosis group

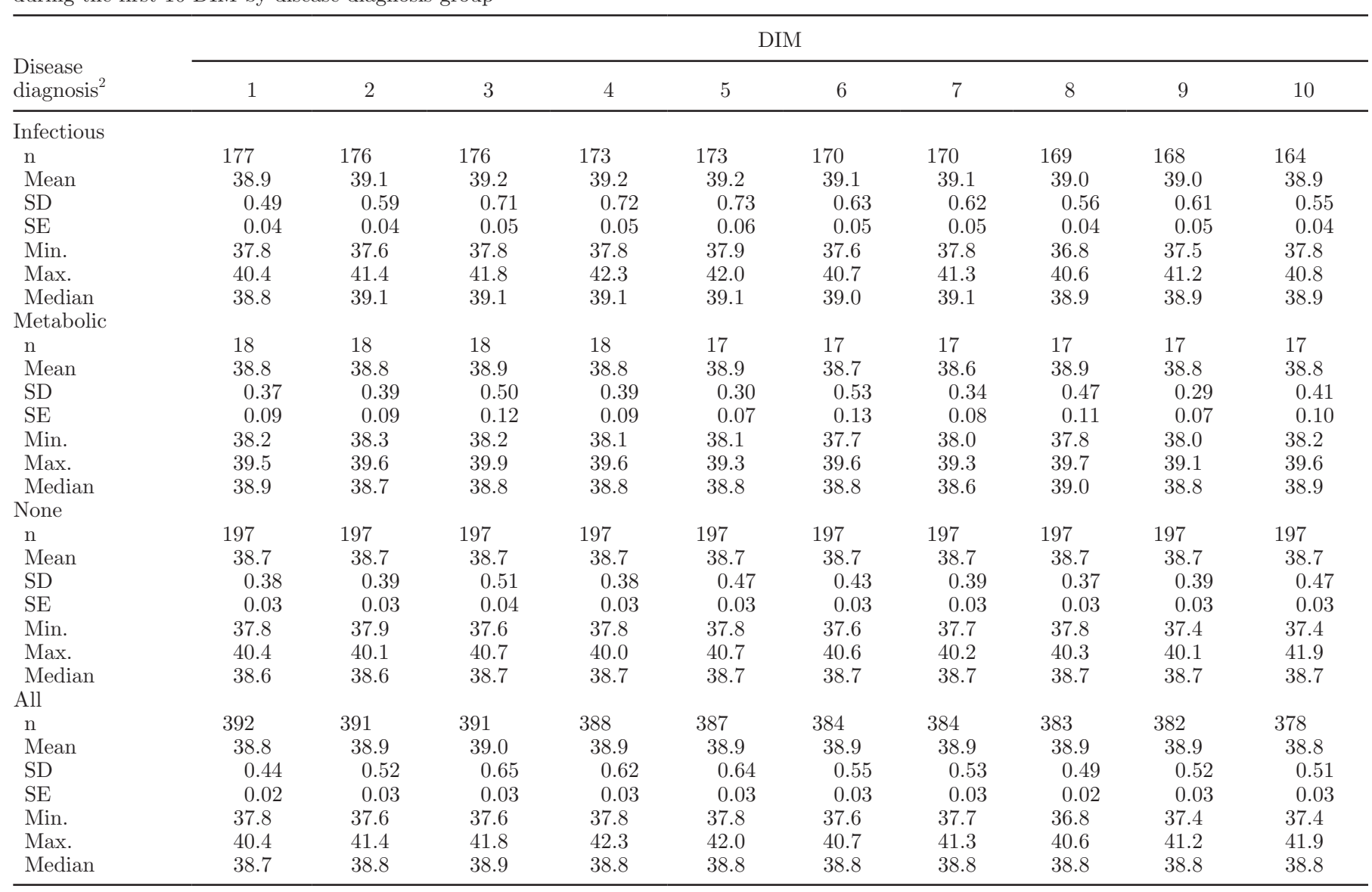

${ }^{1}$ Decreasing cow numbers over the first 10 DIM reflects removal from the herd during that time period.

${ }^{2}$ Cows in the infectious group were diagnosed with mastitis, metritis, or pneumonia; cows in the metabolic/digestive group were diagnosed with milk fever, digestive upset, retained placenta, displaced abomasum, or diarrhea, with a rectal temperature $<39.4^{\circ} \mathrm{C}$; and those in the none group had no disease diagnoses during the first 10 DIM. Cows in the infectious group may have also had a metabolic/digestive disease diagnosis.

al., 2001; Benzaquen et al., 2007; Wagner et al., 2008). It has been suggested that an elevated RT in presumed healthy postpartum cows may be the result of tissue damage associated with the trauma of calving (Wagner et al., 2008). Of the 118 multiparous cows in the defined healthy (NONE disease group), 18 (15\%) had an RT $>39.5^{\circ} \mathrm{C}$, the upper end of the normal range established in the current study. Eleven of those $18(61 \%)$ did not have an RT exceeding the threshold temperature until $\geq 5$ DIM. Similarly, of the 79 primiparous cows in the NONE group, 11 (14\%) had an RT $>39.6^{\circ} \mathrm{C}$, the upper end of the normal range established in the current study. Seven of those 11 (64\%) did not have an RT exceeding the threshold temperature until $\geq 5$ DIM. These data suggest that trauma associated with calving is an unlikely explanation for approximately $60 \%$ of the defined healthy cows that had an elevated RT during the first 10 DIM.

Of NONE group cows with an RT exceeding their respective threshold temperature, $69 \%$ (20/29) did so only on 1 of the first 10 DIM. The elevated RT observed in these cows may have been associated with measurement error or represent normal variation in the population. Six of the remaining 9 cows had 2 or more consecutive days with an elevated RT, suggesting they may have had undetected infectious disease. Wagner et al. (2008) found $66 \%$ of healthy cows had at least $1 \mathrm{RT}$ measurement $>39.5^{\circ} \mathrm{C}$ when measurements were taken every $4 \mathrm{~h}$ during the first 10 DIM. Only 14 and $26 \%$ of the 35 healthy cows in that study had an $\mathrm{RT}>39.5^{\circ} \mathrm{C}$ at the 0400 and $0800 \mathrm{~h}$ measurements, respectively. These findings were similar to those of the current study where a single daily measurement was taken between 0600 and $0800 \mathrm{~h}$.

In the model including all cows (Table 4) as well as the model that included only NONE disease group cows, neither EASE nor twin birth were associated with RT during the first 10 DIM. The lack of association when disease diagnosis group was included in the model is likely the result of the well-documented association 
Table 4. Fixed effects, df, and error df of the final mixed model ${ }^{1}$ with repeated measures to identify factors associated with the rectal temperature of 392 Holstein dairy cows during the first 10 DIM

\begin{tabular}{|c|c|c|c|}
\hline Effect $^{2}$ & df & $\begin{array}{c}\text { Error } \\
\text { df }\end{array}$ & $P$-value \\
\hline Calving ease & 1 & 868 & 0.550 \\
\hline Twin births & 1 & 878 & 0.166 \\
\hline Parity & 1 & 866 & $<0.001$ \\
\hline Month of calving & 1 & 866 & $<0.001$ \\
\hline DIM (1 to 10$)$ & 9 & 3,322 & 0.044 \\
\hline Disease group ${ }^{3}$ & 2 & 814 & $<0.001$ \\
\hline Disease group $\times$ DIM & 18 & 3,466 & $<0.001$ \\
\hline
\end{tabular}

${ }^{1}$ Residual parameter estimate $=0.2647 \pm 0.0071$.

${ }^{2}$ Calving ease $=$ assisted $(\mathrm{n}=127)$ or unassisted $(\mathrm{n}=265)$; twin births $=$ yes $(\mathrm{n}=23)$ or no $(\mathrm{n}=369)$; parity $=$ primiparous $(\mathrm{n}=178)$ or multiparous $(\mathrm{n}=214)$; month of calving $=$ June or July.

${ }^{3}$ Cows in the infectious group $(\mathrm{n}=177)$ were diagnosed with mastitis, metritis, or pneumonia; cows in the metabolic/digestive group $(\mathrm{n}=$ 18) were diagnosed with milk fever, digestive upset, retained placenta displaced abomasum, or diarrhea, with a rectal temperature $<39.4^{\circ} \mathrm{C}$; and those in the none group $(\mathrm{n}=197)$ had no disease diagnoses during the first 10 DIM. Cows in the infectious group may have also had a metabolic/digestive disease diagnosis.

between dystocia and postpartum disease (Sheldon et al., 2009) that was supported by the current study.

An association between parity and RT was identified with primiparous cows having a higher RT compared with multiparous cows accounting for EASE, twin birth, month of calving, and disease group (Figure 2). This association was found when only NONE disease group cows were included in the model as well, but was influenced by DIM. Primiparous cows had slightly higher RT versus multiparous cows, but only during the first 5 DIM. Bewley et al. (2008) identified an association between RT and parity; however, they did not

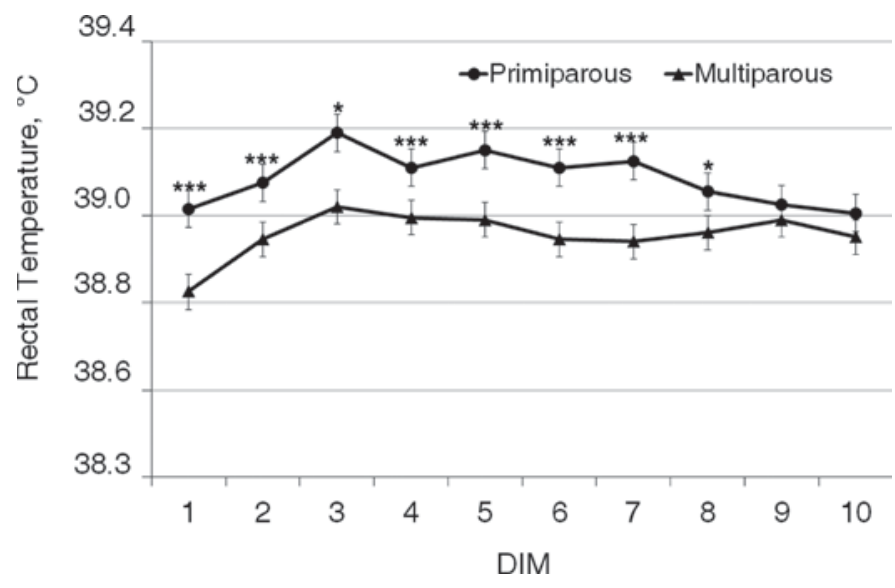

Figure 2. Least squares means $( \pm \mathrm{SE})$ rectal temperature in ${ }^{\circ} \mathrm{C}$ during the first 10 DIM for primiparous $(\mathrm{n}=178)$ and multiparous $(\mathrm{n}=214)$ Holstein dairy cows, accounting for calving ease (unassisted or assisted calving), health status (infectious, metabolic, or no disease diagnosis during 1 to $10 \mathrm{DIM})$. Primiparous was different from multiparous at that DIM, ${ }^{*} P<0.05,{ }^{* * *} P<0.001$. report the difference observed between primiparous and multiparous cows. In contrast, Kristula et al. (2001) did not identify a difference in RT by parity. The conflicting results may be due to a difference in data analysis, as the current study involved multivariate analysis accounting for other factors and repeated measures, whereas Kristula et al. (2001) performed a univariate analysis of the mean and $95 \%$ confidence interval of parity groups for each of the first 10 DIM. The current study only included data from June and July (warm summer months). Kristula et al. (2001) included retrospective data from an almost 2-yr period that included all seasons; however, the potential effect of season on RT was not evaluated. Because this difference was observed in defined healthy (NONE disease group) cows, suggests that during the warm summer months the RT of immediate postpartum primiparous cows is higher than that of multiparous cows. Cows calving in July had a slightly higher RT than those calving in June $\left(0.1^{\circ} \mathrm{C}\right)$, which may have been associated with the $3.4^{\circ} \mathrm{C}$ higher average ambient temperature observed in July over both years of the study.

Diurnal variation in the body temperature of dairy cattle has been well described and is characterized by an early morning nadir (0600 to $0900 \mathrm{~h}$, coincident with morning milking) and a later-day peak that lags 2 to $5 \mathrm{~h}$ behind peak ambient temperatures (Araki et al., 1984; Bewley et al., 2008; Kendall and Webster, 2009). Vickers et al. (2010) observed a $0.1^{\circ} \mathrm{C}$ higher mean vaginal temperature in cows with retained placenta versus those without over 2 to 10 DIM. Interestingly, higher

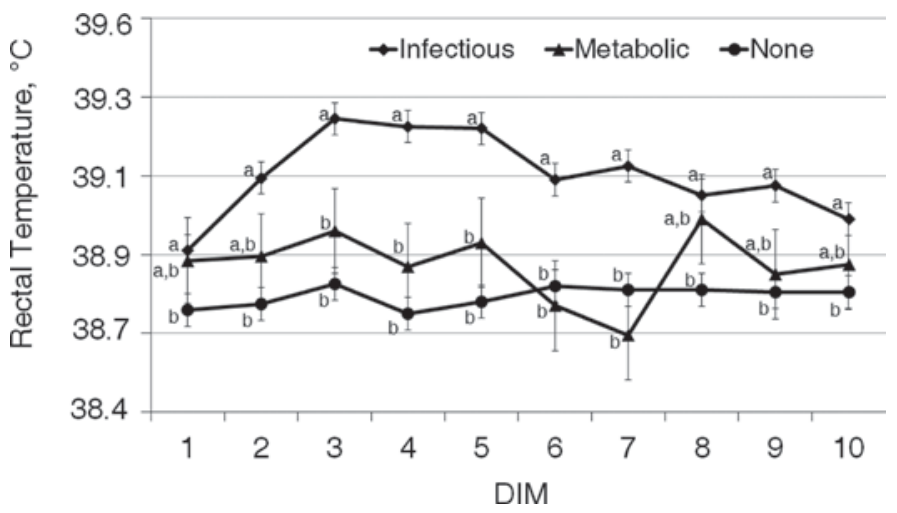

Figure 3. Least squares means $( \pm \mathrm{SE})$ rectal temperature in ${ }^{\circ} \mathrm{C}$ during the first 10 DIM for Holstein dairy cows with a metabolic (n $=18$ ), an infectious $(\mathrm{n}=177)$, or no (none, $\mathrm{n}=197$ ) health event recorded during the first 10 DIM, controlling for parity, calving ease, twinning, and month fresh. Metabolic health events included milk fever, digestive upset, retained placenta, displaced abomasum, and diarrhea with a rectal temperature $<39.4^{\circ} \mathrm{C}$. Infectious health events included mastitis, metritis, and pneumonia with or without a concurrent metabolic health event. Data points within a DIM value with different letters were different $(P<0.014)$. 


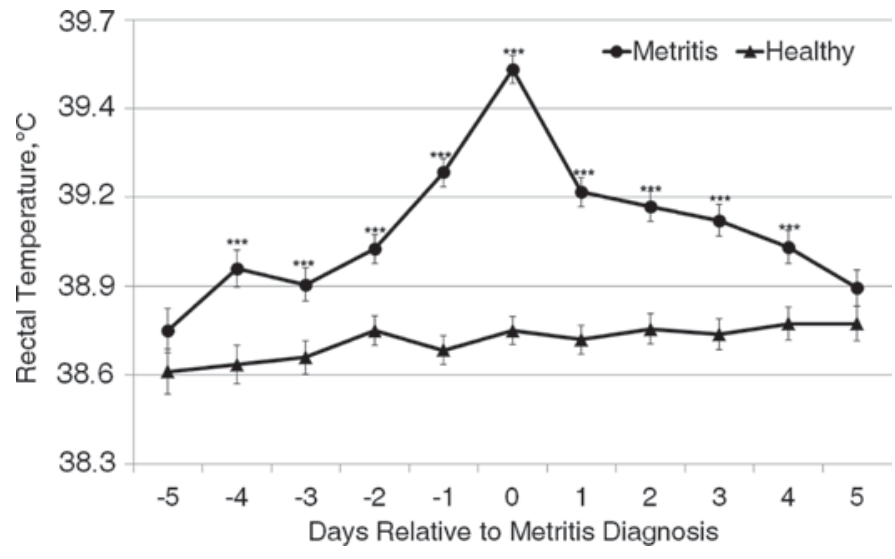

Figure 4. Least squares means $( \pm \mathrm{SE})$ rectal temperature in ${ }^{\circ} \mathrm{C}$ during the first 10 DIM for Holstein dairy cows diagnosed with metritis $(\mathrm{n}=145)$ and those without any disease diagnoses (healthy, $\mathrm{n}=$ 145), matched by parity and calving ease. Rectal temperature in cows with metritis was different than that in healthy cows at that DIM, $* * * P<0.001$.

average vaginal temperatures in retained placenta cows were observed from approximately 0600 to $1200 \mathrm{~h}$ and approximately 2000 to $0300 \mathrm{~h}$, suggesting the common morning RT observation time $(0600$ to $0800 \mathrm{~h}$ in the current study) may be the best to observe differences between normal and abnormal cows. Four of the 7 cows in that study also had infectious disease diagnoses (mastitis, metritis, and respiratory) that likely influenced the average vaginal temperature over 2 to 10 DIM.

Data from defined healthy (NONE disease group) cows was used to determine the normal range of RT by parity during the first 10 DIM. A commonly used statistical method for determining the normal range is to calculate the mean \pm twice the standard deviation of the population (Bollinger, 1992). By this method, the upper limit of the normal range for primiparous cows was $39.6^{\circ} \mathrm{C}$ and that of multiparous cows was $39.5^{\circ} \mathrm{C}$. These values both exceed the high end of the reported normal range of dairy cattle $\left(39.2^{\circ} \mathrm{C}\right.$; Andersson and Jónasson, 1993). Cows with an RT exceeding these values during the first 10 DIM would be good candidates for further evaluation to identify potential infectious disease. The postpartum RT normal ranges identified in the current study support the empirically derived RT thresholds commonly used in postpartum monitoring programs. Further work is needed to determine if the parity difference in RT is observed during other seasons of the year and to determine the ideal RT threshold to identify postpartum cows requiring special attention.

Evaluation of diagnostic test performance is based on comparison with a gold standard test believed to accurately identify truly diseased animals. Metritis is associated with elevated RT postpartum; however, lacking a single gold standard test for metritis, the true disease status of postpartum cows remains uncertain. The use of a lower RT cutoff to identify potentially diseased primiparous cows as described by Kristula et al. (2001) is not supported by the results of the current study, as this would likely result in a higher false positive rate if such cows have a postpartum RT that is normally higher than that of multiparous cows.

Almost one-third of all cows were diagnosed with metritis during the first 10 DIM. The highest RT was observed on the day of metritis diagnosis (Figure 4). These results support Benzaquen et al. (2007), except that the RT of cows with metritis was higher than that of NONE group cows up to $4 \mathrm{~d}$ before diagnosis in the current study versus $3 \mathrm{~d}$ in the prior study. Benzaquen et al. (2007) and Kristula et al. (2001) both reported a substantial decrease in RT the day following metritis diagnosis, which was explained as a response to treatment. A similar drop in RT on the day after metritis diagnosis was observed in the current study as well, despite 34\% (50 of 145) of the cows diagnosed with metritis not being treated with antibiotics. These were cows with an abnormal uterine discharge, most with an $\mathrm{RT}>39.5^{\circ} \mathrm{C}$ that were not identified by farm personnel who evaluated postpartum cows by visual observation alone. A drop of $0.2^{\circ} \mathrm{C}$ was observed $1 \mathrm{~d}$ after diagnosis and a $0.4^{\circ} \mathrm{C}$ drop by $2 \mathrm{~d}$ after diagnosis in those 50 cows that were not treated (data not shown). This suggests the drop in RT observed in previous studies evaluating metritis treatment may not be entirely due to treatments given (Kristula et al., 2001; Zhou et al., 2001; Benzaquen et al., 2007). It is possible that the cows with metritis that did not receive treatment in the current study had less severe disease than those identified by farm personnel and those described in previous studies. The potential effect of transrectal uterine massage was not evaluated in this study. It seems unlikely that the small amount of discharge expressed from the large postpartum uterus with metritis would have much benefit or influence on RT.

\section{CONCLUSIONS}

Factors associated with postpartum RT in dairy cattle for the first 10 DIM included parity, month of calving, and an infectious disease diagnosis, particularly the diagnosis of metritis. Although the highest RT were observed on the third day after calving, the magnitude was significantly different based on parity and disease diagnosis, with the highest observed in primiparous cows and those with infectious disease. The normal RT of dairy cattle in the immediate postpartum period, during the warm summer months, is potentially higher than the normal RT generally reported for dairy cattle. Furthermore, the upper threshold defining fever may 
be different for primiparous compared with multiparous cows. The clinical relevance of these findings and their implications for postpartum monitoring programs requires further investigation.

\section{ACKNOWLEDGMENTS}

We thank S. M. Scott, S. E. Dobberstein and J. Rassmussen (former veterinary students at Washington State University, Pullman) for their technical assistance, and W. R. Wailes of the Dept. of Animal Sciences at Colorado State University (Fort Collins) for financial support.

\section{REFERENCES}

Andersson, B. E., and H. Jónasson. 1993. Temperature regulation and environmental physiology. Pages 886-895 in Dukes' Physiology of Domestic Animals. 11th ed. M. J. Swenson and W. O. Reece, ed. Cornell University Press, Ithaca, NY.

Araki, C. T., R. M. Nakamura, L. W. G. Kam, and N. Clarke. 1984. Effect of lactation on diurnal temperature patterns of dairy cattle in hot environments. J. Dairy Sci. 67:1752-1760.

Benzaquen, M. E., C. A. Risco, L. F. Archbald, P. Melendez, M. J. Thatcher, and W. W. Thatcher. 2007. Rectal temperature, calving-related factors, and the incidence of puerperal metritis in postpartum dairy cows. J. Dairy Sci. 90:2804-2814.

Bewley, J. M., M. E. Einstein, M. W. Grott, and M. M. Schutz. 2008. Comparison of reticular and rectal core body temperatures in lactating dairy cows. J. Dairy Sci. 91:4661-4672.

Bollinger, P. B. 1992. Introduction to quality control and quality assurance in hematology. Pages 532-545 in Clinical Hematology: Principles, Procedures, Correlations. C. A. Lotspeich-Steininger, E. A. Stiene-Martin, and J. A. Koepke, ed. J. B. Lippincott Co., Philadelphia, PA.

Burfeind, O., M. A. G. von Keyserlingk, D. M. Weary, D. M. Veira, and W. Heuwieser. 2010. Short communication: Repeatability of measures of rectal temperature in dairy cows. J. Dairy Sci. $93: 624-627$.
Dinsmore, R. P., R. D. Stevens, M. B. Cattell, M. D. Salman, and S. F. Sundlof. 1996. Oxytetracycline residues in milk after intrauterine treatment of cows with retained fetal membranes. J. Am. Vet. Med. Assoc. 209:1753-1755.

Drillich, M., O. Beetz, A. Pfützner, M. Sabin, H. J. Sabin, P. Kutzer, H. Nattermann, and W. Heuwieser. 2001. Evaluation of a systemic antibiotic treatment of toxic puerperal metritis in dairy cows. J. Dairy Sci. 84:2010-2017.

Kendall, P. E., and J. R. Webster. 2009. Season and physiological status affects the circadian body temperature rhythm of dairy cows. Livest. Prod. Sci. 125:155-160.

Kristula, M., B. I. Smith, and A. Simeone. 2001. The use of daily postpartum rectal temperatures to select dairy cows for treatment with systemic antibiotics. Bovine Practitioner 35:117-125.

Sheldon, I. M., J. Cronin, L. Goetze, G. Donofrio, and H.-J. Schuberth. 2009. Defining postpartum uterine disease and the mechanisms of infection and immunity in the female reproductive tract in cattle. Biol. Reprod. 81:1025-1032.

Sheldon, I. M., A. N. Rycroft, and C. Zhou. 2004. Association between postpartum pyrexia and uterine bacterial infection in dairy cattle. Vet. Rec. 154:289-293.

Smith, B. I., G. A. Donovan, C. Risco, R. Littell, C. Young, L. H. Stanker, and J. Elliott. 1998. Comparison of various antibiotic treatments for cows diagnosed with toxic puerperal metritis. J. Dairy Sci. 81:1555-1562.

Smith, B. I., and C. A. Risco. 2005. Management of periparturient disorders in dairy cattle. Vet. Clin. North Am. Food Anim. Pract. 21:503-521.

Stevens, R. D., R. P. Dinsmore, and M. B. Cattell. 1995. Evaluation of the use of intrauterine infusion of oxytetracycline, subcutaneous injections of fenprostalene, or a combination of both, for the treatment of retained fetal membranes in dairy cows. J. Am. Vet. Med. Assoc. 207:1612-1615.

Vickers, L. A., O. Burfeind, M. A. G. von Keyserlingk, D. M. Veira, D. M. Weary, and W. Heuwieser. 2010. Technical note: Comparison of rectal and vaginal temperatures in lactating dairy cows. J. Dairy Sci. 93:5246-5251.

Wagner, S. A., D. E. Schimek, and F. C. Cheng. 2008. Body temperature and white blood cell count in postpartum dairy cows. Bovine Practitioner 42:18-26.

Zhou, C., J. F. Boucher, K. J. Dame, M. Moreira, R. Graham, J. Nantel, S. Zuidhof, L. Arfi, R. Flores, G. Neubauer, and J. Olson. 2001. Multilocation trial of ceftiofur for treatment of postpartum cows with fever. J. Am. Vet. Med. Assoc. 219:805-808. 